\title{
A presença de Michel Foucault na produção científica nacional da Biblioteconomia e Ciência da Informação
}

\author{
Michel Foucault's presence in the national scientific production of Library and Information \\ Science
}

\begin{abstract}
Gabrielle Francinne de S. C. Tanus Doutora em Ciência da Informação pela Universidade Federal de Minas Gerais - UFMG, Brasil. Professora do Departamento de Ciência da Informação da Universidade Federal do Rio Grande do Norte UFRN, Brasil.

E-mail: gfrancinne@gmail.com ORCID: https://orcid.org/0000-0003-2463-7914
\end{abstract}

\begin{abstract}
Daniela Cândido da Silva Discente do curso de Biblioteconomia da Universidade Federal do Rio Grande do Norte - UFRN, Brasil. E-mail: danielacandidos@ufrn.edu.br
\end{abstract}

Amanda Ingrid Silva de Silva Discente do curso de Biblioteconomia da Universidade Federal do Rio Grande do Norte - UFRN, Brasil. E-mail: amanddaaguiiar@gmail.com

\section{Resumo}

Michel Foucault é um dos mais importantes autores das Ciências Sociais e Humanas (CSH), responsável por uma diversidade de publicações. A Biblioteconomia e a Ciência da Informação inserem-se no rol das CSH, apropriandose das correntes de pensamento produzidos pelas ciências, consolidando o diálogo. Deste modo, a partir de um estudo bibliométrico o objetivo desta pesquisa é mapear a presença de Michel Foucault na produção científica nacional da Biblioteconomia e Ciência da Informação. Para tanto, foi selecionada a Base de Dados de Periódicos em Ciência da Informação (BRAPCI), que indexa os artigos de periódicos nacionais impressos e eletrônicos da área. A coleta de dados foi empreendida em janeiro de 2020, de modo que a cobertura da pesquisa fosse de 1972 a 2019, sendo realizada a partir da consulta dos termos "Foucault" e "Michel Foucault". Foi observado a partir da sistematização dos 128 artigos selecionados: ano de publicação, autoria, periódico, palavras-chaves, temáticas dos artigos e análise das citações. Foram citadas 362 obras de Michel Foucault, entre livros, capítulos de livros e artigos. Percebemos que Foucault é um referencial teórico-metodológico para a Biblioteconomia e Ciência da Informação, estando presente desde a década de 1990 no cenário nacional, sobretudo com a "Arqueologia do saber". Os resultados apontaram também uma concentração das citações em artigos associados aos "Estudos Históricos e Epistemológicos da Ciência da Informação", "Informação, Educação e Trabalho" e "Organização e Representação do conhecimento".

Palavras-chaves: Epistemologia. Ciências Sociais e Humanas. Bibliometria. Michel Foucault.

\begin{abstract}
Michel Foucault is one of the most important authors of Social and Human Sciences (CSH), responsible for a diversity of publications. Library and Information Science are included in the list of $\mathrm{CSH}$, appropriating the currents of thought produced by the sciences, consolidating the dialogue. Thus, from a bibliometric study, the objective of this research is to map the presence of Michel Foucault in the national scientific production of Library and Information Science. To this end, the database of brazilian publications in Information Science (BRAPCI) was selected, which indexes articles from national printed and electronic journals in the area. Data collection was undertaken in January 2020, so that the research coverage was from 1972 to 2019, being carried out by consulting the terms "Foucault" and "Michel Foucault". It was observed from the systematization of the 128 selected articles: year of publication, authorship, periodical, keywords, themes of articles and analysis of citations. 362 works by Michel Foucault were cited, including books, book chapters and articles. We realize that Foucault is a theoreticalmethodological framework for Library and Information Science, having been present since the 1990s on the national scene, especially with the "Archeology of knowledge". The results also pointed to a concentration of citations in articles associated with the "Historical and Epistemological Studies of Information Science", "Information, Education and Work" and "Knowledge Organization and Representation".
\end{abstract}

Keywords: Epistemology. Social and Human Sciences. Bibliometrics. Michel Foucault.

InCID: R. Ci. Inf. e Doc., Ribeirão Preto, v. 11, n. 1, p. 52-72, mar./ago. 2020.

DOI: 10.11606/issn.2178-2075.v11i1p52-72 


\section{Introdução}

Michel Foucault (1926-184) é um dos mais proeminentes autores das Ciências Sociais e Humanas (CSH), responsável por uma extensa produção de textos publicados e traduzidos em diversos idiomas - que são lidos e citados também em várias áreas do conhecimento. Ele foi professor da cátedra "História dos Sistemas do Pensamento", no Collège de France, de 1970 até 1984 (ano da sua morte), sua vasta produção é dividida de modo didático em três momentos: arqueológico $^{1}$, genealógico ${ }^{2}$, e ético ${ }^{3}$, em que se ocupou com mais ênfase nos respectivos domínios do saber (discurso), do poder (dispositivo) e dos sujeitos (ética e com o cuidado de si). Na verdade, tais classificações servem mais para agrupar as obras a partir de um fio condutor do pensamento, do que promover a exclusão de suas ideias de um momento para o outro. Esses agrupamentos são uma construção intencional que visam facilitar a apropriação de seu pensamento a partir desses arranjos constantemente presentes nas produções de especialistas acerca de sua obra - uma unidade discursiva profunda e não imediata que se revela na operação interpretativa e definida por uma certa função de expressão (FOUCAULT, 2000).

Foucault, ao analisar os saberes (científicos ou não), incluindo outras produções discursivas ou não discursivas como são as práticas promove uma ruptura com os estudos históricos e epistemológicos anteriores, os quais abordavam os documentos escritos como única fonte verdadeira e objetiva. A concepção predominante de ciência ainda seguia a lógica de uma evolução ou progresso inserida em uma história linear e contínua, em que as descontinuidades e as rupturas deveriam ser apagadas (MACHADO, 2006). Para a arqueologia importa os acontecimentos e as condições sociais de produção das práticas e formações discursivas, que são um conjunto de enunciados localizados em um espaço e tempo definidos, dando forma as epistemes. Ele também rompe com uma tradição filosófica francesa, ao estudar temas distantes

\footnotetext{
${ }^{1}$ Nesse primeiro momento, estão os livros: "História da loucura" (1961), "Nascimento da clínica" (1963), “As Palavras e as coisas" (1966) e "Arqueologia do saber" (1969); este último livro concentra-se na compreensão metodológica - de seu método arqueológico - trabalhado nos livros anteriores.

${ }^{2}$ Esse segundo momento de seu pensamento tem como marco de transição a sua aula inaugural "A ordem do discurso", ministrada em 1970. As obras "Vigiar e punir" (1975) e "História da sexualidade, 1: vontade de saber" (1976), bem como a obra "Microfísica do poder" (este uma reunião de outros textos do autor pós-mortem).

${ }^{3} \mathrm{O}$ terceiro momento de seu pensamento compreende a "História da sexualidade 2: o uso dos prazeres" (1984), "História da sexualidade 3: o cuidado de si" (1984) e "História da sexualidade 4: as confissões da carne" (este publicado pós-mortem). A extensão do pensamento foucaultiano não se restringe às obras supracitadas, pois ele é conhecido também pela diversidade de outras produções - palestras, entrevistas, aulas ministradas, conferências em eventos etc. - algumas delas estão reunidas na coleção "Ditos e Escritos", composta por mais de dez volumes, entre outros livros e livros organizados.
} 
ou não legitimados como é o caso da loucura, do doente, da medicina social, da sexualidade, do poder, das instituições de sequestro, da disciplina, da ética, do cuidado de si, entre outros.

Castro (2009) demonstra que a instauração de um segundo momento de Foucault decorreu da necessidade de analisar para além dos "acontecimentos arqueológicos" e "acontecimentos discursivos", desvelando dentro dessas categorias as relações de força, de poder, de luta, das estratégias e dos dispositivos que se manifestam de modos diversos nas sociedades e nas instituições. O poder é dissociado da concepção de posse (propriedade) e da visão do poder centrado na figura do Estado (visão unitária) e das Leis (visão judiciária). Em uma virada pós-estruturalista com Foucault o poder, passa, então, a ser visto como relação, uma prática, um dispositivo, o poder se exerce e se encontra disperso em toda a estrutura social. $\mathrm{O}$ poder circula não sendo mais da ordem da posse, de quem tem ou não tem, como se fosse uma coisa material. Particularmente, no momento genealógico, Foucault se interessa pela analítica do poder na "sociedade do espetáculo", nomeada, posteriormente, de "sociedade disciplinar", onde revela o exercício do poder disciplinar nas instituições como: prisão, quartéis, fábricas e escola, as quais em comum fabricam “corpos dóceis” (FOUCAULT, 2011).

No terceiro momento, Foucault discute a questão da ética, do cuidado consigo, das técnicas de si - técnicas pelas quais os indivíduos se compõem como sujeito moral ou sujeito ético. Concentra-se, assim, para além do sujeito-saber e do sujeito-poder, em um sujeito-ético, buscando perceber a hermenêutica dos sujeitos, suas formas de subjetivação, por meio dos sentimentos, valores, das técnicas dos governos de si e dos outros. O biopoder e a biopolítica são dois conceitos trabalhados por Foucault para designar o exercício do poder sobre os indivíduos, controle dos corpos, e sobre o controle da população pelo Estado, o que conduz a um outro conceito relevante da sua obra que é o da "governamentalidade". O poder individualizante sobre os corpos é exercido pelas "tecnologias do eu" que agem no controle e na regulação da população cumprindo uma "arte de governar", conforme os interesses do Estado (FOUCAULT, 1999). Como visto, o poder também se faz presente nesse momento, ao lado da busca incessante pela compreensão do sujeito, elementos centrais do pensamento foucaultiano.

O poder, intimamente vinculado com o saber, produz os campos científicos, estes nomeados pelo seu contemporâneo Pierre Bourdieu (1994). Assim, ao considerar a Biblioteconomia e a Ciência da Informação como campos científicos, implica compreendê-los como espaços de poder e de luta entre os agentes e as instituições para manter ou transformar 
o campo ou as "formações discursivas", marcadas também pelo exercício da "ordem do discurso" (FOUCAULT, 2000). De modo que, Pierre Bourdieu e Michel Foucault, dois autores franceses, tornam-se indispensáveis em uma agenda epistemológica da ciência, em particular, aqui, da Biblioteconomia e Ciência da Informação. Buschman (2010, p. 3) reforça que Foucault "tem sido apontado como uma das fontes principais na estruturação de um projeto para uma teoria crítica viável para a Biblioteconomia e Ciência da Informação, ou Biblioteconomia". De fato, a configuração delas no rol das Ciências Sociais e Humanas ocasiona, certamente, uma maior influência na construção do conhecimento por meio da apropriação de conceitos e teorias advindas daquela área, em que se localizam como campos científicos específicos, permeados por relações de saber e poder.

Essa presença das correntes de pensamento das Ciências Sociais e Humanas na Biblioteconomia e na Ciência da Informação é claramente desvelada nas produções acadêmicas, seja por meio da manifestação do ordenamento do social, da contradição do social e da construção do social na Biblioteconomia (TANUS, 2017, 2018), ou como também é conhecido pelos paradigmas físico, cognitivo e social da Ciência da Informação (CAPURRO, 2003). Destarte, esse enlace da Biblioteconomia e Ciência da Informação com as Ciências Sociais e Humanas tem sido discutido a partir da apropriação de alguns autores que se debruçam sobre nomes específicos das $\mathrm{CSH}$, a depender do interesse e filiação do autor às "escolas de pensamento". Pesquisas que buscam identificar os artigos que versam sobre epistemologia da Ciência da Informação são também um dos caminhos para se chegar aos autores das Ciências Sociais e Humanas citados pela Ciência da Informação (ARAÚJO, 2009; ARBOIT; BUFREM; FREITAS, 2010; FRANCELIN, 2018; BUFREM, 2018). A presença dos autores deriva de diversas motivações de citação, inclusive há um caminho de pesquisa dentro da "comunicação científica", que discute as "sociologias das citações", os tipos de citação e o comportamento dessa ação de relacionar um texto com outro, um autor com outro, citante e citado (ROMANCINI, 2010).

Particularmente, para além do mapeamento geral dos autores das Ciências Sociais e Humanas que são citados pela Biblioteconomia e Ciência da Informação, faz-se necessário aprofundar as análises, adentrando-se em um autor em específico. Nessa direção, de identificação dos autores das Ciências Sociais e Humanas mais citados na Biblioteconomia e Ciência da Informação, os autores Salcedo, Accioly e Cruz (2020) apresentaram mais de trinta autores, citados pelo menos uma vez. As autoras Tanus e Aguiar (2020) apontaram quatorze 
nomes mais citados na produção indexada pela Base de Dados Referencial de Artigos de Periódicos em Ciência da Informação (BRAPCI), são eles: Michel Foucault, Pierre Bourdieu, Jürgen Habermas, Gilles Deleuze, Paulo Freire, Karl Marx, Pierre Lévy, Walter Benjamin, Edgar Morin, Mikhail Bakhtin, Manuel Castells, Bruno Latour, Peter Berger, Immanuel Kant. Para uma análise mais aprofundada dessa apropriação do autor mais citado apontado pelas duas pesquisas supracitadas, continuamos aqui com Michel Foucault a fim de compreender de modo mais verticalizado a sua presença na Biblioteconomia e Ciência da Informação.

\section{Procedimentos metodológicos}

Para o desenvolvimento desta pesquisa foi selecionada a Base de dados de Periódicos em Ciência da Informação (BRAPCI) ${ }^{4}$, que indexa desde 1972 mais de cinquenta periódicos acadêmicos impressos e eletrônicos. Dos periódicos disponíveis, 40 estão ativos e 17 históricos (descontinuados). Como o objetivo da pesquisa é o de mapear a presença de Michel Foucault na produção nacional da Biblioteconomia e Ciência da Informação, tal escolha vai ao encontro da nossa proposta. A coleta de dados ocorreu em janeiro de 2020, de modo que o recorte temporal compreendeu de 1972, ano de criação dos primeiros periódicos da área (Revista da Escola de Biblioteconomia da UFMG e Ciência da Informação, editada pelo IBICT), e o ano todo de 2019, abrangendo, portanto, 47 anos. A busca com o termo "Foucault" e "Michel Foucault" foi realizada na caixa de busca da base de dados, sem operar com nenhum filtro de seleção. Para tanto, convocamos o método bibliométrico e a análise de citação, que operam com métodos matemáticos e estatísticos para o mapeamento científico e a representação da informação (CAFÉ; BRÄSCHER, 2008).

Dos 137 artigos identificados foi necessário realizar o tratamento dos resultados, isto é, a eliminação de resultados duplicados (mesmo artigo publicado em dois periódicos distintos, mesmo artigo recuperado em razão do título em inglês) e das tipologias entrevista e editorial, configurando, portanto, como resultado válido 128 artigos, os quais foram arrolados individualmente em uma planilha do Excel. Diante do corpus delimitado em 128 artigos, analisamos o ano de publicação, o periódico, os autores e as palavras-chaves. Realizamos também um enquadramento de todos os artigos nos Grupos de Trabalho (GT) do Encontro

\footnotetext{
${ }^{4}$ BRAPCI. Base de dados de periódicos em ciência da informação. Acervo de publicações brasileiras em Ciência da Informação. Paraná, 2017. Disponível em: http://old.brapci.inf.br/index.php. Acesso em: 10 jan. 2020.
} 
Nacional de Pesquisa em Ciência da Informação (ENANCIB) a partir da leitura dos elementos pré-textuais dos artigos (título, resumo, palavras-chaves). Com vistas a relacionar as temáticas dos artigos quanto a apropriação do Michel Foucault a partir dos seus três momentos delineados, buscamos, novamente, analisar os elementos pré-textuais e as referências (póstextual) para delinear a presença e a influência deste autor.

Essa coleta de dados, pautada pelo método bibliométrico permite olharmos para as características quantificáveis dessa produção, ou melhor para o "saber científico registrado" e "as práticas de mensuração da informação" (BUFREM; PRATES, 2006), chegando a considerações importantes para o campo epistemológico da Biblioteconomia e Ciência da Informação. Assim, consideramos que a bibliometria possibilita uma extração de regularidades das formações discursivas, que são reveladas por meio da materialidade dos enunciados produzidos e publicados em artigos científicos. A visualização das citações de Michel Foucault na Biblioteconomia e Ciência da Informação contribui para uma maior claridade do desenvolvimento dos campos científicos, uma vez que convocam esse autor crítico para composição da trama discursiva da pesquisa e do próprio contexto epistemológico. Nessa direção, da bibliometria, como caminho empírico para se chegar os enunciados e as formações discursivas, nos conduz, em alguma medida, a própria arqueologia de Michel Foucault. As referências, documentos citados, são monumentos intencionalmente selecionados pelos autores para a composição de um outro documento-monumento, estabelecendo uma rede e relação de saber e poder.

Essa aproximação entre a bibliometria e a arqueologia foi posta em publicação nacional por Alvarenga (1999). Segundo essa autora a arqueologia consistiria em uma importante fundamentação teórico-metodológica, que permitiria ultrapassar os limites quantitativos da bibliometria, mostrando uma abertura ao pensamento crítico e as novas categorias de análise. Corroboramos com a articulação entre a bibliometria e a arqueologia do saber, tendo em vista a discussão epistemológica que ambas são capazes de fomentar. A bibliometria tem sido empreendida inclusive em outros estudos que tem servido como um caminho para o conhecimento dos territórios das formações discursivas, dos campos científicos, da Biblioteconomia e Ciência da Informação, seja na pesquisa ou no ensino, por exemplo (SHIKIDA, 2012; TANUS, 2013). Como dito, embora a bibliometria tenha seu objetivo muito bem delineado, de observar o registrado, a análise do discurso a partir da arqueologia foucaultiana compreende os discursos para além da sua unidade física. Como o livro sendo 
uma dessas unidades que se abre e fecha é preciso ir além, pois "Por mais que o livro se apresente como um objeto que se tem na mão; por mais que ele se reduza ao pequeno paralelepípedo que o encerra: sua unidade é variável e relativa. Assim que a questionamos, ela perde sua evidência. Não se indica a si mesma, só se constrói a partir de um campo complexo do discurso" (FOUCAULT, 2000, p. 26).

Em síntese, a análise de citação registra os enlaces dessa rede discursiva entre os textos e a produção do conhecimento científico que não se realiza sem as práticas de (re)conhecimento dos trabalhos realizados anteriormente. Dito isto, "as citações são uma prova empírica de relações entre os conhecimentos que formam os campos do saber" (ALVARENGA, 1999, p. 7), e é por meio das citações que empreendemos esta pesquisa. E são as citações que permitem também a recorrência dos discursos, podendo a partir delas potencializar as regularidades e as positividades dos enunciados em um tempo histórico. Para Foucault (2000, p. 142) a positividade de um discurso caracteriza a "unidade através do tempo e muito além das obras individuais, dos livros e dos textos", e com ela que chegamos ao a priori histórico, as condições de realidade dos enunciados. E, por meio, das emergências observadas na Biblioteconomia e Ciência da Informação que podemos aclarar melhor a construção dessa rede discursiva.

\section{Resultados e discussão}

Como dito após a "limpeza dos resultados" a busca por Michel Foucault na base de dados Base de dados de Periódicos em Ciência da Informação (BRAPCI) totalizou 128 trabalhos publicados, os quais estão disponíveis em texto completo. Interessante perceber que a apropriação de Foucault na Biblioteconomia e Ciência da Informação na produção científica nacional ocorre a partir da década de 1990. Diante desse resultado, considerado tardio, tendo em vista que os primeiros livros de Michel Foucault datam da década de 1960, consultamos as bases de dados internacionais: Scorpus e Library and Information Science (LISA) ${ }^{5}$ com os seguintes termos de buscas: "Foucault" AND "Library and Information Science". Em ambos os resultados o primeiro trabalho também estava associado a década de 1990, sinalizando uma virada crítica em comunhão com o pensamento foucaultiano. Destarte, no Brasil, o primeiro artigo de 1992, abordou a produção da verdade a partir de Foucault, publicado na revista Ágora

\footnotetext{
${ }^{5}$ LISA. Library and Information Science Abstract. ProQuest. Disponível em: https://searchproquest.ez18.periodicos.capes.gov.br/lisa/index. Acesso em: 02 jan. 2020.
} 
(UFSC). A partir de então podemos ver a presença de Michel Foucault nos artigos, embora em uma frequência pequena, isto é, diferente do esperado. O momento de maior concentração ocorreu em 2010, em razão de um volume especial da revista Educação Temática Digital - ETD (UNICAMP), após essa data houve momentos com maiores e outros com menores citações a Foucault, conforme o Gráfico 1.

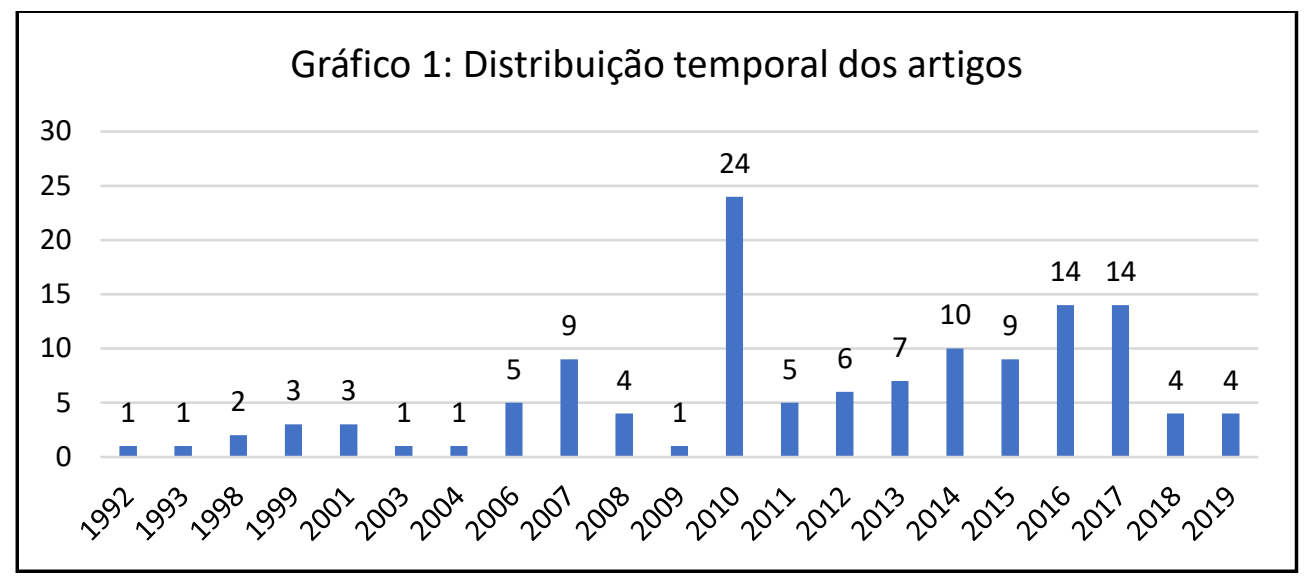

Fonte: Elaborado pelas autoras.

Para analisar em quais periódicos os artigos foram publicados, tivemos que realizar uma padronização dos títulos, pois ora apresentavam por extenso, ora abreviado. Este mesmo recurso foi utilizado para analisar a autoria dos trabalhos. Quanto aos periódicos o resultado foi bastante disperso, registrando 34 títulos diferentes de periódicos. Em segundo lugar, encontramos os trabalhos apresentados e publicados nos anais do ENANCIB, os quais são indexados pela BRAPCI, concentrando 16 publicações. Com um único artigo publicado, foram identificados onze periódicos, com dois artigos foram seis periódicos, com três artigos foram nove periódicos, e com quatro periódicos foram dois. Expomos nominalmente no Gráfico 2 apenas aqueles periódicos com mais de cinco artigos: ETD — Educação Temática Digital (UNICAMP), com 32 trabalhos; Anais do ENANCIB (ANCIB), com 16 trabalhos; Ciência da Informação (IBICT), com seis trabalhos; InCID: Revista de Ciência da Informação e Documentação (USP), com seis trabalhos; Em Questão (UFRGS), com cinco trabalhos; Informação \& Sociedade: Estudos (UFPB), com cinco trabalhos. 


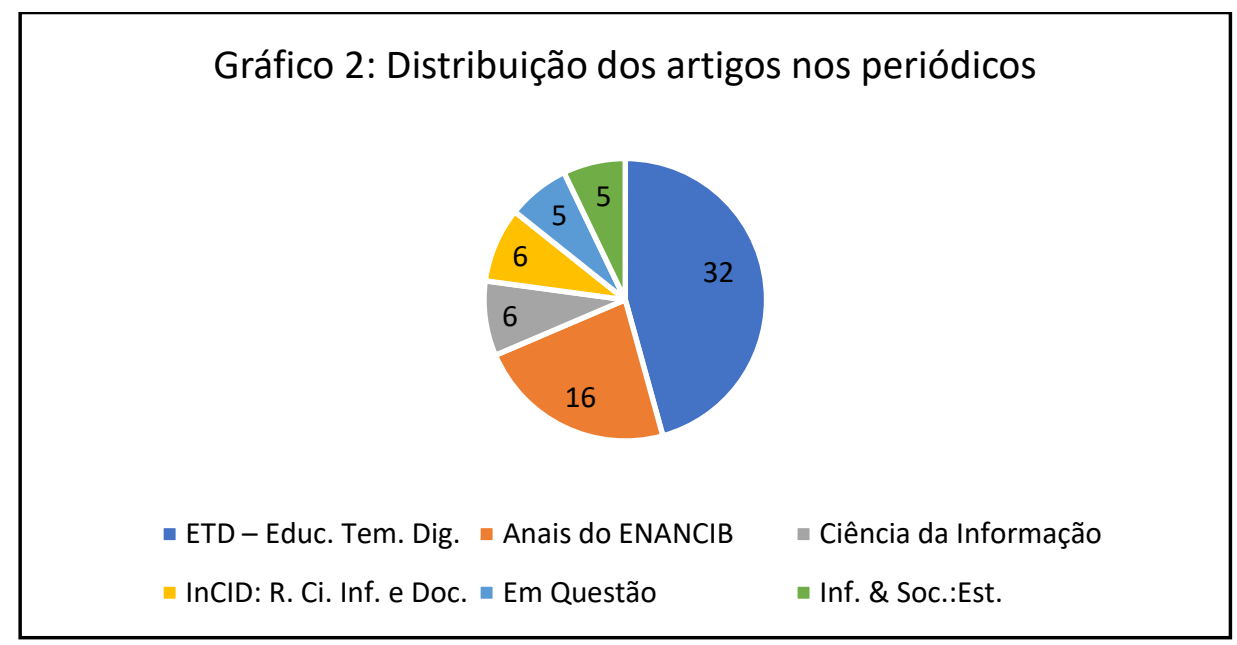

Fonte: Elaborado pelas autoras.

A dispersão de autores que citaram Foucault em suas produções também foi bastante elevada, não podendo dizer que há um núcleo de pesquisadores em torno de sua obra, pelo menos do ponto de vista da análise dos artigos nacionais no que se refere às citações. Foram identificados no total 188 citantes, sendo 160 diferentes entre autores e coautores. Dos 128 artigos, 50 são com coautoria. E quando analisado os sujeitos mais frequentes, chegamos à ocorrência máxima de quatro vezes, que registamos no Quadro 1.

Quadro 1 - Autoria dos artigos

\begin{tabular}{|l|c|l|}
\hline \multicolumn{1}{|c|}{ Nomes } & Freq. & Responsabilidade \\
\hline Nádea Regina Gaspar & 4 & 3 autoria única e 1 coautora \\
\hline Bernardina Maria Juvenal Freire & 3 & 2 autoria única e 1 coautora \\
\hline Larissa de Mello Lima & 3 & 3 coautoria \\
\hline Marcia H. T. de Figueiredo Lima & 3 & 2 autoria única e 1 coautora \\
\hline Maria Aparecida Moura & 3 & 2 autoria única e 1 coautora \\
\hline Regina Maria de Souza & 3 & 2 autoria única e 1 coautora \\
\hline Rodrigo Rabello & 3 & Autoria única \\
\hline Thiago Henrique Bragato Barros & 3 & Autoria única \\
\hline \multicolumn{2}{|c|}{ Fonte: Elaborado pelas autoras. } \\
\hline
\end{tabular}

Para compreender como os autores representavam os assuntos dos artigos coletamos todas as palavras-chaves de cada um dos 128 artigos. Ao final chegamos a um total de 515 ocorrências, sendo 366 termos distintos. As palavras mais frequentes são: Michel Foucault (14 vezes); Análise do discurso (10 vezes); Ciência da Informação (10 vezes); Epistemologia; Dispositivo; Informação; Documento; Memória; Psicanálise (sete vezes cada uma dessas palavras). Percebemos uma grande dispersão, além da consideração de relações interessantes como a presença da análise do discurso e as palavras supracitadas quando se referem as 
produções que citam Michel Foucault, o que dá indícios temáticos para compreensão de uma primeira aproximação. É pela via da análise do discurso, localizada na arqueologia do saber, que Foucault impactou profundamente muitos campos, incluindo a Library and Information Science (DEWEY, 2015). Para complementar a visualização apresentamos a Figura 1 que revela a nuvem de palavras gerada no Wordclouds.

Figura 1 - Nuvem de palavras originada a partir das palavras-chaves dos artigos

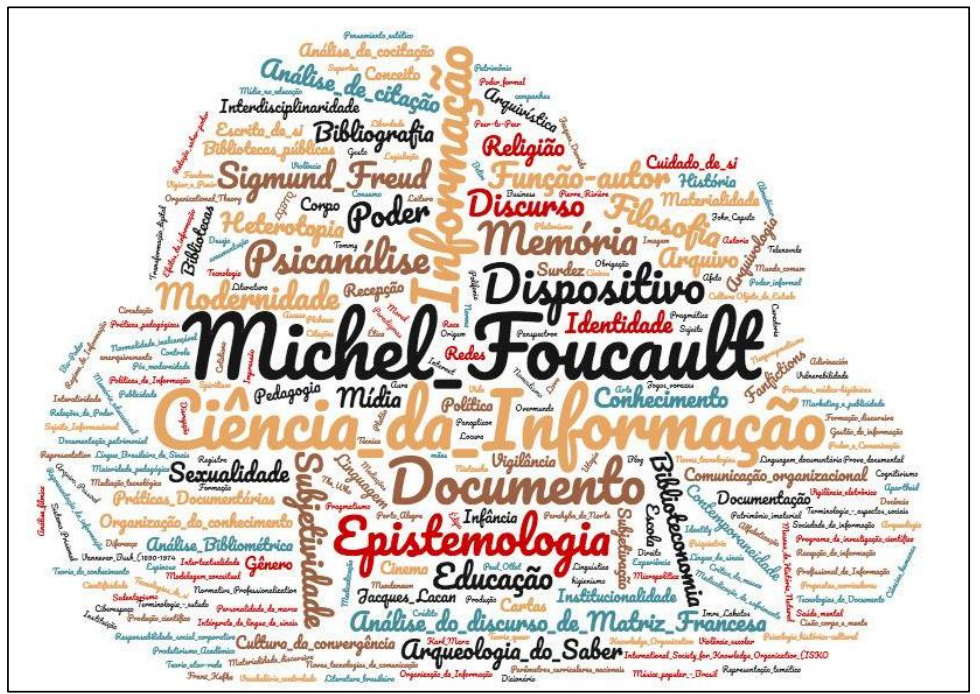

Fonte: Elaborado pelas autoras.

Para adentrar no conteúdo dos artigos realizamos uma leitura dos elementos pré-textuais com o objetivo de compreender a temática dos artigos e articulá-los com os onze grupos de trabalhos do Encontro Nacional de Pesquisa em Ciência da Informação (ENANCIB), principal evento da área da Ciência da Informação no Brasil. Como exposto no Gráfico 3, dos 11 grupos de trabalhos, os com maior ocorrência foram o GT1 e GT6 que tratam respectivamente dos "Estudos Históricos e Epistemológicos da Ciência da Informação" e "Informação, Educação e Trabalho", com 29 e 22 trabalhos. Em terceiro lugar ficou o GT2 "Organização e Representação do conhecimento", com 19 trabalhos, em quarto lugar com GT5 "Política e Economia da Informação", com 12 trabalhos. E com dez trabalhos está o GT10 “Informação e Memória”, o GT11 “Informação e Saúde", com nove trabalhos. O GT3 "Mediação, Circulação e Apropriação da Informação", GT7 "Produção e Comunicação da Informação em Ciência e Tecnologia" e GT9 "Museu, Patrimônio e Informação", apresentaram cinco trabalhos em cada. Com menos trabalhos estão o GT4 "Gestão da Informação e do Conhecimento" com quatro trabalhos, e apenas com um trabalho o GT8 "Informação e Tecnologia". Ademais, desses grupos, sentimos a necessidade de criar uma outra categoria nomeada de "Diversos", pois sete trabalhos não apresentaram nenhuma proximidade com a Biblioteconomia e a Ciência da Informação. Essas 
publicações estão vinculadas a dois periódicos interdisciplinares, a saber: "Educação Temática Digital”, com seis artigos, e "Comunicação e Informação”, com um artigo.

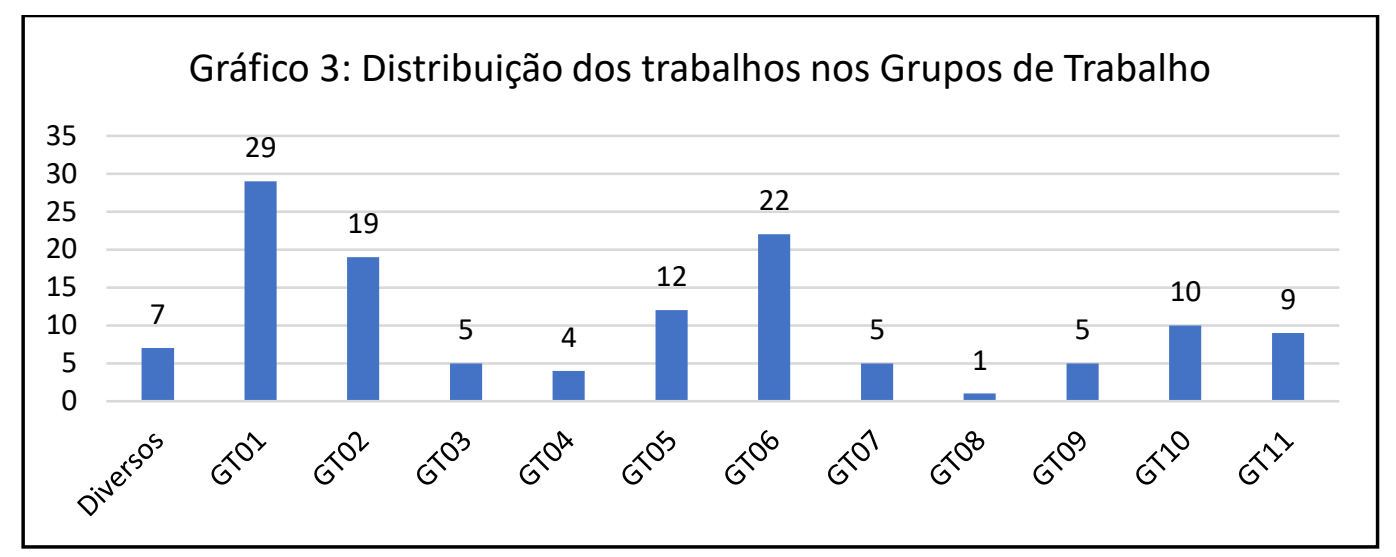

Fonte: Elaborado pelas autoras.

Por fim, com o intuito de identificar quais as obras do Foucault estavam sendo citadas, realizamos também a coleta sistemática nas referências de todos os artigos. Os 128 artigos acumularam 362 referências relacionadas a Michel Foucault. Operamos com a classificação tipológica dessas referências a fim de identificar suas tipologias, aparecendo as seguintes categorias: artigos, capítulos de livros, livros. Interessante perceber que os autores citam seus livros na íntegra, isto é, a referência do livro no todo e não de suas partes, o que geraria uma referência de capítulo. O quantitativo de 288 livros, contudo, não significa títulos diferentes, sendo encontrados 56 títulos (entre livros que foram editados em vida e post-mortem do autor), conforme Apêndice A. E com 67 citações estão os capítulos de livros e com sete citações estão os artigos, conforme disposto no Gráfico 4.

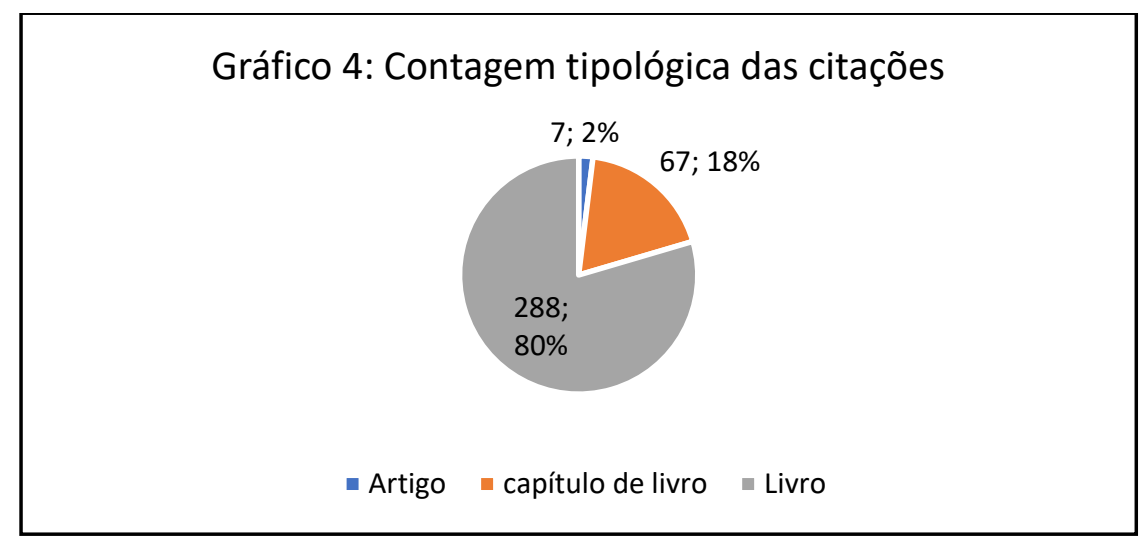

Fonte: Elaborado pelas autoras.

Para aprofundar nessas citações, buscamos então sistematizar todas essas referências, buscando responder: Quais obras do Michel Foucault são mais citadas? Agrupamos todos os 
títulos citados em português, mesmo quando as obras eram citadas em outros idiomas realizamos essa tradução com o objetivo de obter um quantitativo da obra citada. Para o próprio Foucault (2003, p. 259) seus livros podem ser utilizados como instrumentos, ou melhor, como:

livros-bomba quer dizer, livros que sejam úteis precisamente no momento em que alguém os escreve ou os lê [...]. Os livros deveriam ser espécies de bombas e nada mais. Depois da explosão, se poderia lembrar às pessoas que esses livros produziram um belíssimo fogo de artifício.

Identificamos que o livro mais citado é "A arqueologia do saber", sendo ainda interessante perceber que nenhum autor referenciou algum capítulo desse livro, sendo citado nas referências na íntegra. O segundo livro mais citado foi o "Vigiar e Punir" que se encontra dentro de um momento genealógico, diferente do primeiro e do terceiro livro mais citados que se localizam no momento arqueológico. Vale a pena assinalar que os três momentos de Foucault estão presentes no Quadro 2, que sinaliza as obras mais citadas. O momento ético encontra-se presente com a obra "Hermenêutica do sujeito". Dentre os capítulos mais citados o único registro foi do livro a "Microfísica do poder", que é uma reunião de aulas e textos traduzidos por Roberto Machado, um dos estudiosos da obra de Michel Foucault e Gilles Deleuze.

Quadro 2 - Obras mais citadas de Michel Foucault

\begin{tabular}{|l|c|c|}
\hline \multicolumn{1}{|c|}{ Título } & Livro & Capítulo \\
\hline A arqueologia do saber & 46 & - \\
\hline Vigiar e punir & 31 & - \\
\hline As palavras e as coisas & 28 & - \\
\hline A ordem do discurso & 24 & - \\
\hline Microfísica do Poder & 23 & 6 \\
\hline A História da Sexualidade I & 22 & - \\
\hline A verdade e as formas jurídicas & 13 & - \\
\hline A Hermenêutica do sujeito & 10 & - \\
\hline \multicolumn{2}{|c|}{ Fonte: Elaborado pelas autoras. } & \\
\hline
\end{tabular}

Importante destacar a pesquisa de Scott Dewey (2016), que buscou analisar a apropriação de Michel Foucault, especialmente, pela via da arqueologia do saber, a partir da análise da citação de duas obras: "Arqueologia do saber" e as "Palavras e as coisas" na produção científica da Library and Information Science (LIS). Foram analisados os principais periódicos que disponibilizam o texto completo, no período de 1990 a 2015, isto é, quinze anos, com a intenção de delinear a influência desse intelectual e o comportamento de cada citação em seis níveis, do mais básico, citação bibliográfica ao mais complexo, que envolve uma assimilação profunda. Nesta pesquisa, foram localizados 188 artigos que citaram as duas obras, em 63 
distintos periódicos, todavia 259 artigos citavam outras obras de Foucault, que não compuseram o estudo, como as obras também conhecidas "Vigiar e Punir" e "História da sexualidade".

Dewey (2016) ainda dentro dessa análise apontou que apenas 38 artigos, isto é, uma minoria das citações pode ser classificada como de "uso muito substancial", onde múltiplos parágrafos ou páginas dedicadas ampla ou inteiramente às ideias de Foucault são realizadas na construção dos artigos da LIS. Enquanto, uma maioria, 150 artigos citaram essas obras de passagem, fazendo uso breve, uso limitado, com quase nenhum uso visível de Foucault. Portanto, para Dewey (2016) contrariamente às expectativas iniciais, os trabalhos em questão citam pouco essas duas obras e quando citam, em sua maioria, costumam ser pouco significativas, sendo mais de passagem. Em resumo, ironicamente, dois dos livros mais importantes sobre análise do discurso parecem desaparecer nesse discurso, cedendo espaço mais aos comentadores (fontes secundárias) do que o próprio Michel Foucault.

Sem adentrar nessa classificação dos níveis de apropriação das referências, retornamos aos resultados da análise das citações da pesquisa em tela, dos 67 capítulos de livros citados o maior quantitativo está vinculado a um título específico, o livro organizado por Dreyfus \& P. Rabinow, traduzido em português como "Michel Foucault: uma trajetória filosófica", publicado pela Forense universitária. A soma da coleção "Ditos e escritos" é de 26 citações somente de seus capítulos. Essa coleção é uma reunião em onze volumes de seus textos, palestras e aula, realizadas ao longo de sua vida. Sendo que nem todos os volumes foram citados no todo ou em partes, apresentamos os livros citados e os capítulos no Quadro 3.

Quadro 3 - Obras mais citadas da Coleção Ditos e Escritos de Michel Foucault

\begin{tabular}{|l|c|c|}
\hline \multicolumn{1}{|c|}{ Coleção "Ditos e escritos" } & Livro & Capítulo \\
\hline Ditos e escritos I (problematização do sujeito) & 3 & 3 \\
\hline Ditos e escritos II (arqueologia das ciências) & 3 & 4 \\
\hline Ditos e escritos III (estética, literatura e cinema) & - & 6 \\
\hline Ditos e escritos IV (estratégia, poder-saber) & 3 & 6 \\
\hline Ditos e escritos V (ética, sexualidade, política) & - & 6 \\
\hline Ditos e escritos VI (repensar a política) & 1 & - \\
\hline Ditos e escritos IX (genealogia da Ética) & - & 1 \\
\hline
\end{tabular}

Fonte: Elaborado pelas autoras.

Dos artigos de autoria de Michel Foucault citados nos artigos da Biblioteconomia e Ciência da Informação analisados, o mais citado está traduzido e foi publicado na década de 1970. A Revista Tempo Brasileira continua vigente e publica textos de interesse social, 
histórico, filosófico e literário. Ao percebemos a manifestação de um artigo traduzido há várias décadas, é possível reafirmar que Foucault (e seus livros também traduzidos nessa época) demorou para ser citado na Biblioteconomia e Ciência da Informação. Os artigos de Foucault citados apenas uma vez estão associados às publicações nacionais dos anos de 1999, 2007, 2010 e 2018.

Quadro 4 - Artigos citados de Michel Foucault

\begin{tabular}{|l|r|}
\hline $\begin{array}{l}\text { Resposta a uma questão. Revista Tempo Brasileiro, Rio de Janeiro, n. 28, p. 79, } \\
\text { jan./mar., 1972. }\end{array}$ & 3 \\
\hline $\begin{array}{l}\text { About the beginning of the hermeneutics of the self: two lectures at Dartmouth. } \\
\text { Political Theory, v. 21, p. 198-227, May 1993. }\end{array}$ & 1 \\
\hline De espaços outros. Estudos Avançados, v. 27, n.79, p. 113-122, 2013. & 1 \\
\hline The subject and power. Critical Inquiry, v. 8, p. 777-795, Summer 1982. & 1 \\
\hline $\begin{array}{l}\text { Of other spaces, utopias and heterotopias. Architecture, mouvement, continuité. v. 5, p. } \\
\text { 46-49, 1984. }\end{array}$ & 1 \\
\hline
\end{tabular}

Fonte: Elaborado pelas autoras.

De um modo geral, quanto a apropriação das obras de Michel Foucault percebemos uma dispersão significativa entre seus livros e capítulos de livros na Biblioteconomia e Ciência da Informação, e diminuta quando comparada com seu impacto nas Ciências Sociais e Humanas. As obras mais citadas no Quadro 1 perpassam com mais vigor o momento arqueológico e genealógico. Dentre as obras dessa fase arqueológica citadas estão: “A arqueologia do saber” e “As palavras e as coisas", da fase genealógica estão: "Vigiar e Punir", “A ordem do discurso", "Microfísica do poder" e "A verdade e as formas jurídicas". Em pesquisa realizada no Google Scholar, em 2004, por Elliott Green (professor da London School of Economics) constatou que Foucault está entre os autores mais citados das Ciências Sociais, com as obras "Vigiar e Punir" que recebeu mais 60 mil citações e "História da sexualidade III", com 47 mil citações. Ao realizar a busca por Foucault no referido buscador, em janeiro de 2020, o resultado foi de mais de dois milhões de ocorrência.

O reflexo das obras mais citadas de Michel Foucault, conforme visto nos quadros 2, 3 e 4, encontram uma ressonância no Gráfico 5, onde é apresentado uma classificação dos 128 artigos localizados dentro dos momentos foucaultianos. Esse exercício de aproximação dos artigos aos momentos arqueológico, genealógico e ético é importante para compreender como Michel Foucault se faz presente, embora toda classificação seja arbitrária e limitada, em um duplo movimento de inclusão e exclusão. Essa aproximação ocorreu por meio da análise temática dos artigos e, em seguida, as próprias referências confirmaram essa direção classificatória e de enquadramentos por semelhança e regularidade discursiva. Como podemos 
perceber a arqueologia e a genealogia predominam nos artigos de Biblioteconomia e Ciência da Informação.

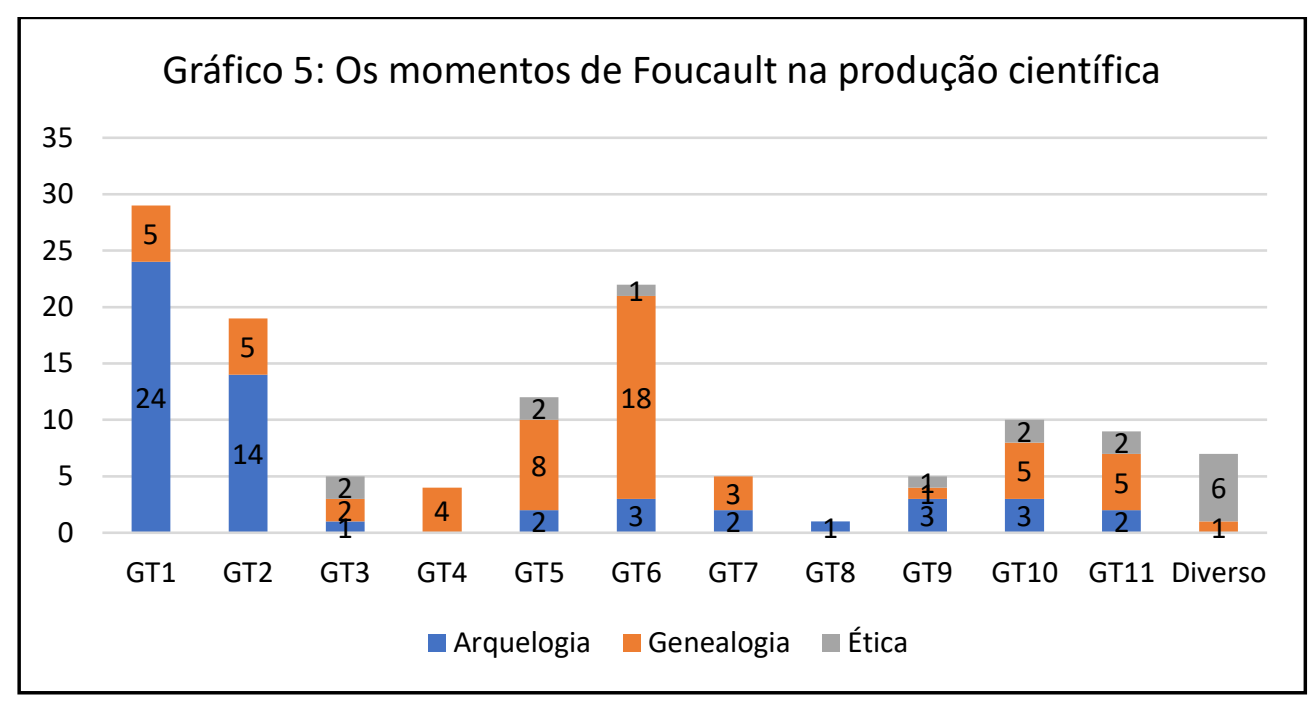

Fonte: Elaborado pelas autoras.

Em especial, o GT1 e GT2 concentram produções que podem ser localizadas dentro desse momento arqueológico, uma vez que se apropriam da "arqueologia do saber", e de seu vocabulário, em especial, da "análise do discurso", tanto para a construção histórica e epistemológica quanto para a construção discursiva da organização dos saberes. Nesse primeiro GT se faz presente a episteme, as condições de possibilidade dos discursos, a formação discursiva, a problemática do documento e da história. No GT2 a arqueologia é também trazida por meio da reflexão sobre os discursos, os enunciados, os conceitos e, sobretudo, o poder de nomear, classificar e ordenar - presente nos sistemas de organização dos conhecimentos e na modelação de um domínio, prática e comunidade discursiva. Outro destaque envolvendo a arqueologia recai nos estudos do GT6 em que a relação do poder é discutida a partir do ensino, do currículo e das práticas pedagógicas. As relações de poder-saber são também tensionadas por meio das instituições como as bibliotecas e as escolas e a ação de seus profissionais neste GT6.

O momento genealógico é manifestado com mais vigor nas produções cujos temas envolvem as políticas públicas, o estado, a economia, os regimes de informação sob uma influência foucaultiana, as quais fazem parte deste GT5 "Política e economia da informação". A noção de dispositivo como um conjunto heterogêneo que engloba discursos, instituições, arquiteturas, decisões regulamentares, leis, normas, enunciados, o dito e o não dito, promovem 
uma abertura em rede do próprio exercício do poder no campo social. O saber-poder é o centro da genealogia, diferente da arqueologia que o centro repousa sobre a linguagem e os discursos, de modo que a analítica do poder-dispositivo-verdade encontra uma abertura maior. A ética é o único momento que não aparece em todos os grupos de trabalho, sendo também menos presente por meio das citações a obras dessa fase centrada no "sujeito". A categoria "Diverso" abrange a maior quantidade de produções, as quais inclusive não foram classificadas dentro dos GT’s, justamente, por não abrangerem as temáticas oriundas da Biblioteconomia e nem da Ciência da Informação. Os GT10 e GT11 por versarem acerca da informação, memória e saúde, trazem em suas produções a questão da ética, de uma genealogia do sujeito, do cuidado de si, concentrando-se no sujeito e nas práticas de si como discussões centrais.

Acreditamos que o uso de Michel Foucault torna o campo mais aberto as relações com as Ciências Sociais e Humanas, afastando a Biblioteconomia e Ciência da Informação de um isolacionismo ou mesmo das compreensões fisicalistas e mentalistas, marcas do paradigma físico e cognitivo da Ciência da Informação (CAPURRO, 2003). Gloria Leckie e John Buschman (2010) destacam a importância da área em apropriar dos estudos críticos e dos diversos autores das Ciências Sociais e Humanas, entre eles, o próprio Michel Foucault, para que possam promover discursos mais alinhados com os problemas sociais, e, consequentemente, práticas mais críticas e significativas diante dos contextos ou "no plano de uma pesquisa do ordinário" (FOUCAULT, 2000, p. 15). Essa presença de Michel Foucault na Biblioteconomia e Ciência da Informação nos revela, nesse primeiro momento, uma indispensável abertura dos campos às linhas de pensamento das Ciências Sociais e Humanas. É a partir de Foucault também que a Biblioteconomia e Ciência da Informação tem seus caminhos abertos para a insurgência de uma outra epistemologia e de temáticas como, por exemplo, "neodocumentação", "regimes de informação", "análise de domínio", "organização dos saberes", entre outras, as quais ancoram-se na compreensão pós-estruturalista e de influência foucaultiana. 


\section{Considerações finais}

Foi observado a partir da sistematização dos 128 artigos analisados que Michel Foucault constitui em um autor presente nos estudos da Biblioteconomia e Ciência da Informação. A sua aparição na década de 1990 na área no âmbito nacional vai também ao encontro da literatura internacional, configurando uma virada epistemológica, ainda que tímida, em razão da instauração mais clara de um paradigma social. Todavia, não se pode apontar uma tendência constante de sua presença e nem um crescimento de citação as suas obras, pois o maior pico de registros ocorreu devido um periódico específico (ETD - Educação Temática Digital), que promoveu dois números temáticos, em 2010: "Psicanálise e Filosofia: um diálogo possível?" e "Foucault e a Educação: é preciso pensar e agir de outros modos". Sendo que ao longo dessas décadas contempladas não houve um diferencial quanto ao impacto das citações, não é possível inclusive dizer em uma tendência de citações.

A dispersão dos periódicos e dos autores que citam Michel Foucault parece também não originar um núcleo bem delimitado. A própria diversidade de palavras-chaves também chama a atenção, pois poderiam ser melhor harmonizadas justamente para facilitar a recuperação da informação. Quanto a essa falta de padronização das palavras-chaves podemos atribuir a diferentes fatores: falta de um vocabulário controlado nos periódicos, falta de um controle de indexação dos assuntos pela base ora utilizada, ou mesmo a falta de um rigor dos autores ao atribuírem as palavras-chaves. Interessante perceber que as autoras Café e Bräscher (2008) ao analisar as dificuldades encontradas por pesquisadores na área de bibliometria concluíram que: “[...] de maneira geral, as dificuldades se concentram principalmente na padronização de títulos de periódicos e de nomes de autor (descrição física), assim como na diversidade de representações de assunto (descrição de conteúdo)".

Quando Foucault é apropriado pela área, em grande parte, essa via se faz pela análise do discurso, uma das marcas de seu primeiro momento, o arqueológico. Para a Biblioteconomia e Ciência da Informação a arqueologia do saber ampara os estudos epistemológicos, da organização e do ensino, tendo em vista a ocorrência de trabalhos classificados dentro dos GT1, GT2 e GT6. Com Foucault não é possível pensar em instituições e informações objetivas, imparciais, neutras, como também o usuário como um sujeito passivo sem discutir as relações de poder, que marcam esse sujeito histórico, ético e discursivo. São os discursos, as formações discursivas, que produzem e são produzidos pelos sujeitos imersos nas epistemes 
(FOUCAULT, 2000). As visões de mundo dos sujeitos estão localizadas na estrutura social, ou melhor, nas epistemes de cada momento, que produzem saberes e poderes com efeitos distintos. Esperamos, assim, que o pensamento foucaultiano dentro da Biblioteconomia e Ciência da Informação contribua veementemente para o deslocamento de visões redutoras, mecânicas e isoladas dos fenômenos sociais e informacionais.

Desejamos que mais pesquisas se debrucem sobre os referenciais teóricosmetodológicos das Ciências Sociais e Humanas para iluminar os caminhos da Biblioteconomia e da Ciência da Informação. A leitura e a apropriação de autores das Ciências Sociais e Humanas, entre eles, o próprio Michel Foucault é um caminho interessante para se pensar de modo mais crítico e histórico as relações humanas e sociais. Como sugeriu o próprio Michel Foucault em abrir a "caixa de ferramentas" (FOUCAULT, 2003) de sua produção, podendo, portanto, o leitor servir de seus conceitos, teorias, frases ou palavras, pois muito bem o fez fabricando para que os outros se sirvam dentro da conjuntura presente e do quadro teórico que coadune com o desenvolvimento da pesquisa na Biblioteconomia e Ciência da Informação.

\section{Referências}

ALVARENGA, Lídia. Bibliometria e arqueologia do saber de Michel Foucault: traços de identidade teórico-metodológica. Ciência da Informação, Brasília, v. 27, n. 3, maio 1999.

ARAÚJO, Ronaldo Ferreira. Leituras de Bruno Latour na Ciência da Informação: analisando citações. Ponto de Acesso, Salvador, v. 3, n. 3, p. 299-316, dez. 2009.

ARBOIT, Aline Elis; BUFREM, Leilah Santiago; FREITAS, Juliana Lazzarotto. Configuração epistemológica da Ciência da Informação na literatura periódica brasileira por meio de análise de citações (1972-2008). Perspect. ciênc. inf., Belo Horizonte, v. 15, n. 1, p. 18-43, abr. 2010.

BOURDIEU, Pierre. O campo científico. In: ORTIZ, Renato (org.). Pierre Bourdieu. 2 ed. São Paulo: Ática, 1994.

BUFREM, Leilah Santiago; PRATES, Yara. O saber científico registrado e as práticas de mensuração da informação. Ciência da Informação, Brasília, v. 34, n. 2, mar. 2006.

BUFREM, Leilah Santiago. A prática da pesquisa e os quadros teóricos concorrentes no campo de produção científica em ciência da informação. P2P \& INOVAÇÃO, Rio de Janeiro, v. 4, n. 1, p. 35-58, set./fev. 2018. 
BUSCHMAN, John. Transgredir ou estagnar? desafiando Foucault na teoria da

Biblioteconomia e Ciência da Informação (BCI). InCID: R. Ci. Inf. e Doc., Ribeirão Preto, v. 1, n. 1, p. 3-31, 2010.

CAFÉ, L.; BRÄSCHER, M. Organização da informação e bibliometria. Encontros Bibli: Revista Eletrônica de Biblioteconomia e Ciência da Informação, n. esp. 1, p. 54-75, 2008.

CAPURRO, Rafael. Epistemologia e ciência da informação. In: ENCONTRO NACIONAL DE PESQUISA EM CIÊNCIA DA INFORMAÇÃO, 5., 2003, Belo Horizonte. Anais... Belo Horizonte: ANCIB, 2003. p. 1-28.

CASTRO, Edgardo. Vocabulário de Foucault: um percurso pelos seus temas, conceitos e autores. Belo Horizonte: Autêntica, 2009.

DEWEY, Scott Hamilton. (Non-)use of Foucault's archaeology of knowledge and order of things in LIS journal literature, 1990-2015. Journal of Documentation, v. 72, n. 3, p. 454489, 2016.

FOUCAULT, Michel. Em defesa da sociedade: curso no collège de France (1975-1976). São Paulo: Martins Fontes, 1999.

FOUCAULT, Michel. A arqueologia do saber. 6. ed. Rio de Janeiro: Forense-Universitária, 2000.

FOUCAULT, Michel. Diálogo sobre o poder. In: MOTTA, Manoel Barros da (org.). Ditos e escritos: ética, estratégia, poder-saber. Tradução de Vera Lúcia Avellar Ribeiro. Rio de Janeiro: Forense Universitária, 2003. v. 4.

FOUCAULT, Michel. Vigiar e punir: nascimento da prisão. Trad. Raquel Ramalhete. 39. ed. Petrópolis: Vozes, 2011.

FRANCELIN, M. M. Epistemologia da Ciência da Informação: evolução da pesquisa e suas bases referenciais. Perspect. ciênc. inf., Belo Horizonte, v. 23, n. 3, p. 89-103, set. 2018.

LECKIE, Gloria; BUSCHMAN, John. Introduction: The necessity for theoretically informed critique in library and information science (LIS). In: LECKIE, Gloria; GIVEN, Lisa M.; BUSCHMAN, John E. Critical theory for library and information science: exploring the social from across the disciplines. Santa Barbara, California: Libraries Unlimited, 2010.

MACHADO, Roberto. Foucault, a ciência e o saber. Rio de Janeiro: J. Zahar, 2006.

ROMANCINI, Richard. O que é uma citação? a análise de citações na ciência. Intexto, Porto Alegre, v. 2, n. 23, p. 20-35, jul./dez. 2010.

SALCEDO, Diego; ACCIOLY BEZERRA, Vinicius; CRUZ, Marcílio. Filosofia na Ciência da Informação brasileira: análise de artigos científicos na BRAPCI entre 1972 e 2018.

Logeion: Filosofia da Informação, Rio de Janeiro, v. 6, n. 2, p. 6-21, mar. 2020. 
SHIKIDA, Aparecida Maciel da Silva. Construção e constituição de uma ciência: análise bibliométrica e arqueológica do periódico Ciência da Informação - Brasil. 2012. Tese

(Doutorado) - Universidade Federal de Minas Gerais, Escola de Ciência da Informação, 2012.

TANUS, Gabrielle Francinne de S. C. Cenário acadêmico institucional dos cursos de Arquivologia, Biblioteconomia e Museologia do Brasil. 2013. 242 f. Dissertação

(Mestrado) - Universidade Federal de Minas Gerais, Escola de Ciência da Informação, 2013.

TANUS, Gabrielle Francinne de S. C. As correntes de pensamento das ciências sociais e humanas: enlace com a Biblioteconomia. Ciência da Informação em Revista, Maceió, v. 4, n. 1, p. 3-16, maio 2017.

TANUS, Gabrielle Francinne de S. C. A Biblioteconomia e a "construção do social". Revista Interamericana de Bibliotecología, v. 41, n. 2, p. 167-178, abr. 2018.

TANUS, Gabrielle Francinne de S. C.; AGUIAR, Amanda Ingrid Silva de. A presença dos autores das ciências sociais e humanas no campo da Biblioteconomia e da Ciência da informação. Logeion: Filosofia da informação, Rio de Janeiro, v. 6, n. 2, p. 22-39, mar. 2020.

\section{APÊNDICE A - RELAÇÃO DAS OBRAS CITADAS DE MICHEL FOUCAULT}

\begin{tabular}{|l|c|c|}
\hline \multicolumn{1}{|c|}{ Título das obras } & Livro & Capítulo \\
\hline A arqueologia do saber & 46 & \\
\hline A coragem da verdade & 1 & \\
\hline A Hermenêutica do sujeito & 10 & \\
\hline A História da Sexualidade I & 22 & \\
\hline A História da Sexualidade II & 9 & \\
\hline A História da Sexualidade III & 5 & \\
\hline A ordem do discurso & 24 & \\
\hline A verdade e as formas jurídicas & 13 & \\
\hline Aesthetics, method, and epistemology & & 1 \\
\hline As palavras e as coisas & 28 & \\
\hline Curso no Collège de France (1975-1976) & & 1 \\
\hline Curso en el Collège de France (1977-1978) & & 1 \\
\hline Curso en el Collège de France (1978-1979) & & 1 \\
\hline Discurso y verdad la antigua & 1 & \\
\hline Ditos e escritos I (problematização do sujeito) & 3 & 3 \\
\hline Ditos e escritos II (arqueologia das ciências) & 3 & 4 \\
\hline Ditos e escritos III (Estética, Literatura e cinema) & & 6 \\
\hline Ditos e escritos III (Estética: literatura e pintura, música e cinema) & 5 & \\
\hline Ditos e escritos IV (estratégia, poder-saber) & 3 & 6 \\
\hline Ditos e escritos IX (genealogia da Ética) & & 1 \\
\hline Ditos e escritos V (ética, sexualidade, política) & & 6 \\
\hline Ditos e escritos VI (Repensar a política) & 1 & \\
\hline
\end{tabular}


Do governo dos vivos

Doença mental e psicologia

Dossier últimas entrevistas

Em defesa da sociedade

Entre filosofía y literatura

Estruturalismo e teoria da linguagem

Ethics: Subjectivity and truth

Ethos der Moderne: Foucaults Kritik der Aufklärung

$\mathrm{Eu}$, Pierre Rivière

Governo de si e dos outros

História da loucura

Language, counter-memory,practice: selected essays and interviews

Michel Foucault: beyond structuralism and hermeneutics

Michel Foucault: entrevistas

Michel Foucault: uma trajetória filosófica

Microfísica do Poder

Nascimento da Biopolítica

O corpo utópico, as heterotopias

O dossier: últimas entrevistas

O nascimento da clínica

O poder psiquiátrico

O que é um autor?

Os anormais

Power/Knowledge: Selected Interviews and Other Writings, 1972-1977

Politics, philosophy, culture: interviews and other writings

Psicanálise, poder e desejo

Resumo dos cursos do Collège de France (1970- 1982)

Segurança, território, população

Tecnologias del yo y otros textos afines

The Foucault reader

The politics of truth

The Tanner lectures on human values

Untying the text: a post-structuralist reader.

Vigiar e punir: nascimento da prisão

\begin{tabular}{l|l}
4 & \\
1 & \\
1 & \\
\hline 7 & \\
\hline 2 & 1 \\
\hline & 1
\end{tabular}

1

\begin{tabular}{|l|l|}
\hline 1 & \\
\hline 4 &
\end{tabular}

6

\begin{tabular}{l|l}
\hline & 4
\end{tabular}

1

\begin{tabular}{l|l} 
& 1 \\
\hline 23 & 9 \\
\hline
\end{tabular}

\begin{tabular}{|l|l|}
1 & \\
\hline 1 & \\
\hline & 1 \\
\hline
\end{tabular}

